\title{
LAS SOCIEDADES ANONIMAS ANTE LA MORAL
}

La reciente publicación de la Carta Pastoral del Excmo. St. Arzobispo de Valencia, sobre La Fratemidad en los Sociedad Anóninas, pone el dia wn tema de gran interés. No precisamente el de la existencia de las sociedades, sino su relación con la Moral.

Fue preocupación del primer Director de nuestra revista, P. Joaquín Azpiazu, quien, por lo mismo, incluyó en su magnífica obra, La moral del hombre de negocios, un ponderado captíulo: «Las S. A. ante la Moral», brillante comentario y moderaización de lo que, en ceñida síntesis, ofrecen algunos manuales de Teología Moral. En esta obra, y en la Pastoral aludida, inspiramos este comentario, de acuerdo con ambas, pretendiendo modestam tamente contribuir a una mayor difusión de las palabras del ilustre Prelado y deseando se realice el que sus ideas «lleven luz $\mathrm{y}$, sobre todo, decisiones de amor fraterno a cuantos, de alguna forma, integran las sociedades anónimas.

Partimos del reconocimiento de la utilidad de las S. A.: «La técnica moderna... hace posible como nunca..., la explotación en gran escala de las tiquezas naturales, conjugando en la empresa grandes masas de capital y grandes masas de trabajo. Esa conjunción trae al mercado cantidades de bienes materiales de tan buena calidad y de tan bajo precio, que antes no se podían ni soñar. Con tales y tantos bienes, puestos al alcance de la mano, se logra elevar el nivel de vida de los aportacionistas de capital y de los aportacionistas de trabajo; en general de todos los ciudadanos... Dignifican al trabajador, ahorrando su fuerza bruta. Llenan, por lo tanto, una función que la actual marcha de la humanidad requiere; función que no podrían llevar a cabo, o la llevarian con harto mayor esfuerzo y desventaja, propietarios particulares y aun grupos de propietarios particulares personalmente responsables» (Pastoral).

Pero tienen sus peligros, que nacen de su mismas caracteristicas: impersonalidad de la sociedad, representada por acciones; responsabilidad de los asociados, limíada a su participación; flexibilidad del mecanismo que permite la acumulación de los capitales superior a la cantidad que, de ordinario, puede reunir el consorcio de particulares, con responsabilidad personal. 
Las consecuencias de esa su democratización teónica -no precisamente en la realidad-en el derecho y en los pactos, ponen de relieven los peligros; entre otros:

- En la práctica, contra el sentido democrätico, una tendencia a la inposición de la voluntad de los grandes accionistas sobre la de los pequeños.

- Con culpa frecuente de los mistnos pequeños accionistas, guienes, por falta de formación o de información, están ausentes de la marcha de la sociedad.

- La facilidad de la compra de acciones, facilita asimismo el cambio de gobierno, con el serio peligro de torcer una primera orientación social, por ignorancia o imposición de intereses privados. La lucha de oposición de intereses, entre grupos de accionistas, hace olvidar fácilmente el interés público y el bien social en cada momento histórico.

- La tendencia al monopolio mata la competencia e impone una especie de dictadura económica, cargando en la política, y rainaado la independencia de la autoridad del Estado.

- Todo ello, dada la limitación de responsabilidades, acrecienta el peligro puesto de relieve en la Pastoral: «el de la deshumanización de los propietarios dadores de trabajo, con los trabajadores que lo ejecutan: técnicos, administrativos, obreros...»

Son muchos los responsables en las sociedades anónimas, más o menos ocultos tras de la «razón social»:

Están los accionistas, en el grado en que se dé su participación. Es muy importante recordar a los accionistas su responsabilidad, y más importante el que ellos la admitan y obren en consecuencia. En opinión de hombres de autoridad, la educación moral de los accionistas tanto como su educación económica, deja mucho que desear. Su responsabilidad moral, lo mismo que la de los administradores y gerentes en su grado, está basada en la naturaleza de la sociedad anónima. Puede considerarse al accionista como propietario, como patrono respecto de los obreros, fiscalizador del personal director bajo su mando. Su participación es, por lo tanto, formal, en todo cuanto hace la sociedad, y de ello es responsable en conciencia, por su parte de propiedad. Su responsabilidad se extiende al objeto y procedimientos de la empresa, la elección de mandatarios, condiciones de trabajo, condiciones de venta del producto.

Contra el cómodo, o cobarde, abstencionismo, basta, a veces, un hombre de conciencia y de iniciativa, para arrastrar a muchos otros de tan buena voluntad, como de limitación de arrestos. Il abstencionismo puede ser, y frecuentemente es, un fallo moral; si el accionista es condueño, tiene las obligaciones de todo dueño, si bien limitadas a las que la legislación positiva le señala; porque puede que, de ordinario, su intervención esté concretada a las Asambleas anuales y revisión de libros.

En principio es deber suyo hacer en pro de la empresa, y de sus socios y trabajadores, cuanto haría en la empresa individual propia, o en una empresa colectiva, como socio. No puede soslayar los problemas de justicia: 
sueddo a los trabajadores, honorarios, retribuciones justas a técricos, ascensos, despidos, comisiones excesivas, compras con primas... «Toda acción de una sociedad anónima debe ser para la conciencia cristiana el fraterno ardabonazo, con frecuencia el angustioso aldabonazo, del trabajador a la puerta del amo» (Pastoral).

II capitulo de deberes carga sobre los consejeros; porque a mayor honor, mayor responsabilidad. La justicia debe salir limpia de su conducta, acruando «con la cabeza económica que tienen y con el corazón de hermanos. que, si no a todas (las empresas), a gran parte de ellas les falta» (Pastoral).

Si su obligación es mirar por el bien de la sociedad, del trabajador, del cliente, de los socios, de los accionistas; falta será, preocupándose exclusiva o preferentemente de la ciestión administrativa o crediticia, descargar en un gerente o empleado, todo lo reserente al personal o al cliente. Tanto más cuanto que, desconociendo el subalteno a veces, to que el anonimato del consejo oculta, no puede proceder como la justicia exigiría. Aunque no se deja de reconocer que el personal numeroso no facilita el cumplimiento de los deberes; y que, en más de una ocasión, será necesario atender al ejercicio de la función directora, mediante Instituciones especiales: Auxiliares sociales, Consejos de fábrica...

Porque son, de ordinario, muy graves, los asuntos que el consejero tiene en la dirección de la empresa, obligación suya es estudiarlos concienzudamente. Afectan a muchos - socios, subordinados y terceros-; no cabe, en limpia conducta moral, querer ignorarlos, no darse por enterado. Existe el llamado pecado de omisión de quien, debiendo actuar por razón de oficio, no actúa.

Se pone a sí mismo trabas para una cumplida actuación quien multiplica sus compromisos. Por la deficiente entrega al estudio del problema, con el peligro de no justificarse el cobro de dietas y honorarios con la mera asistencia corporal, cuando existe evidente desproporción.

Por encima de la aptitud en potencia, está la «affectio societatis», y fácilmente carece el advenedizo, el mero representante, de ese afecto y esa entrega que siguen al conocimiento del fin de la sociedad, y a ese vivir bajo el peso de la tradición que impelen a secundar las exigencias del bien social y que frenan el interés individual, el frio egoísmo.

Se han buscado remedios; lo cual indica que se han visto y ponderado los peligros:

Uno de los remedios está en dar más entrada en la sociedad al pequeño accionista; esos llamados «masa» - por el número y la insuficiente formación sobre su deber-, a la que hay que orientar; "soberano cautivo», al que hay que tutelar y proteger - supuesto que aprenda a reinar-. Su mandato, sus órdenes serán a través del voto, que no parece sea solamente un derecho, sino un deber también. "Todos vosotros, aun los dueños de una sola acción, cuando os presentéis en la asamblea general... o cuando confiéis la represenración a otro, alzad la voz y exigid que la alcen los delegados para que se 
detalle ante todos la faceta humana de la sociedad" (Pastoral). Es una de las razones que fuerzan a refexionar sobre al imporancia del voto.

Hay que poner límite al frecuente olvido de la atencion al trabajador. Ess la sociedad arónima, se dice, un ser impersonal; los accionistas no se sienten responsables; los administradores y los gerentes se preompan, ante rodo, de suministrar dividendos... «Detallándose la marcha econónica de la empresa: activo y pasivo, amortizaciones e inversiones, dividendos al capital..., no se nombra o se alude a ella sin detalle, la parte socia, la parte humana de la misma. Se llevan las sociedades anónimas a puro cálculo económico, cálculo frío, sin amor fraterno.i Y así se explica el egoismo en el reparto del «trigo limpio»; y, cuando, no corre ran limpio, en la solución de golpes de mano antisociales: despido, cierre, paro...

No talta quien sale por la fama de las sociedades anónmas, al compararlas con las empresas individuales, desde el punto de vista del cumplimiento de los deberes sociales. Se insiste demastado sobre el contraste wre las sociedades anónimas y las otras sociedades. Hay ahi una confusión. Cuano las objeciones tienen de cierto se refiere menos a la forma de la sociedad que a las dimensiones de la empresa y a las disposiciones personales de los directores y administradores》 (FalloN, Economia Social). Sin duda había que analizar caso y caso; y el peligro es mayor para quienes, en los incumplimientos, quedan menos al descubierto.

La preocupación por el elemento humano en la empresa, hará exigir que se dé cuenta en la Memoria anual: del número de trabajadores, con las flucruaciones de entradas y despidos y el por qué (tal vez la admisión al trabajo haya sido por imposición de la magnificencia, queriendo borrar el espectro del paro); de las condiciones humanas en que la actividad del trabajador se desarrolla; del sentido social de cuantos se mueven en la empresa; de la relación entre el salario que perciben y el coste de la vida, analizando si van a un ritmo igual...

La obligación de mirar al fin social la fija la teoría de la institución, desarrollada ampliamente por el P. Azpiazu, ea su libro citado. La teoria de 1a «institución» ve la sociedad anónima como una corporación de elementos jerarquizados que tienden a un fin colectivo; un fin, marcado por los contratantes, que da su sello a la institución y que la obliga a no cambiar de rumbo; con una autoridad que dirija todos los actos administrativos a la consecución del fin social.

El nuevo accionista ha de conocer el fin, de antemano, y ha de estar dispuesto a aceptar los actos de la autoridad para lograrlo. Los así dispuestos, mostrarán la «affectio societatis»; serán auténticos accionistas.

Pero comprar paquetes de acciones, inmediatamente antes de una junta general, porque se sabe, o se adivina, un momento de interés, dinerario o de sustitución de consejeros, no sería, evidentemente, in con un claro fin social.

El desarrollo de la actual economia multiplica las acciones al portador, 
camino abierto a la especulación y al frío cálculo económico; más obligado queda quien se liga con acciones nominativas.

La tradición familiar, de vida en una sociedad, da mayores garantías, de conocimiento y entrega al fin, que el juego de los especuladores; que la llegada del advenedizo, que ayer compró acciones, para maziana venderlas con el alza. ¿No cabria un aumento de valor en el voto según el número de años de continuada propiedad?

El voto del accionista es una obligación, pero determinada siempre por el bien de la sociedad; según esto, ¿no habrá ocasiones en que el accionista deberá abstenerse de votar? Por ejemplo si los accionistas son representantes de otra sociedad con intereses opuestos a ésta, o en mera competencia.

Ligado el accionista a la sociedad, por el deseo de procurar el bien común de la misma, a la vez que por la participación en los riesgos que lleva consigo la imposición de dinero en la sociedad, está obligado, en la medida de sus fuerzas, al logro de ese bien común. Y esto lo manifesta por el voto, derecho y deber, que nunca podtá usar -o dejar de usar- en propio provecho o ajeno, contra el biet de la sociedad. No podrá confesar de palabra un amor -affectio- que traiciona con hechos; su voto no podrá ser puñalada trapera, en defensa de otra usociedad». a la que entrega la prueba del amor: las obras. No podrá votar en suministros de materias primas, o en aplicación de tarifas de transportes, o en fijación de precios... de modo que perjudique a la sociedad, pero que le beneficie a él, ligado con otra sociedad de transportes o de materias primas; seria inmoral.

Puede prestarse a inmoralidad la conducta de los que acuden a una junta general como delegados de un número crecido de accionistas, e incluso de miles de acciones, $y$ dirigen los votos correspondientes según interés de poderosas entidades extrañas.

Pero esto es ataque en dos sentidos; espada de dos filos: hiere al representante y al representado; en el caso de la torpe representación al primero; y de falta de información, como para tranquilizarse en conciencia, al segundo.

Otro punto, que trata la Pastoral: la autoridad, la fjeza de la direcciónz, la revocabilidad de consejeros y directores está, en general, en manos del capital; el número de votos, el de accionistas, decide en absoluto. Cabe, sí, el informe previo al pueblo, a la masa de pequeños accionistas; pero ahí estáa la responsabilidad: de los que informan - con su sinceridad contra el engaño-, y de los informados -.por lo menos, con su asistencia.

Puede, en teoría, salir at paso de tales y semejantes abusos, la ley; pero puede la malicia humana conculcarla. Sin conciencia labrada en cristiano, adelantaremos poco, y poco duradero.

F. DEL VALLE 